\title{
Morphological Characteristics of Otoliths for Selected Fish in the Northwest Atlantic
}

\author{
J. J. Hunt \\ Department of Fisheries and Oceans, Marine Fish Division \\ St. Andrews, New Brunswick, Canada
}

\begin{abstract}
The relationships between otolith dimensions and fish size for six demersal and two pelagic species were examined and found to be both curvilinear and species-specific. Otolith morphometric observations included length for all species examined and weight, width, volume, cross-sectional area and location of the focal point for selected species. Regression models relating each otolith morphometric parameter to fish length are provided. Statistical tests to examine correlation between left and right otolith dimensions were carried out and, for redfish, correlation in otolith morphology between sexes was also analyzed. There appeared to be no statistically significant difference between left and right otolith or between sexes. The significance of each parameter for estimating fish length was examined and a multiple regression model determined. Otolith weight appeared to have the best discrimination for estimating fish length as well as the easiest parameter to measure.
\end{abstract}

\section{Introduction}

Morphological characteristics of fish otoliths are highly variable between species, ranging from the relatively simple disc shape of some flatfish (Pleuronectidae) to the irregular shape of others such as redfish (Sebastes sp.). Harkonen (1986) describes characteristic otolith shapes for Northeast Atlantic finfish. Otolith growth is related to increase in size of the fish and generally follows an allometric increase in dimensions (Chilton and Beamish, 1982). In some species the morphological outline of the otolith may undergo substantial changes with increasing size and may also be variable in fish of the same size, although the characteristic shape of otoliths can usually be determined at a relatively small size (pers. obs.). Messieh and MacDougall (MS 1984) note that within species some population components may have significant differences in otolith morphometrics.

In addition to the use of otoliths for estimating age of fish, they may also be used to characterize stock specific differences or to interpolate size-atage based on some relation between otolith and fish dimension (Hunt, 1979). Numerous studies have been undertaken to estimate size at some earlier age (back-calculation) based on relationships between otolith dimension and fish size. More recent studies have applied otolith morphometrics to models for estimating fish age (Boehlert, 1985; Pawson, 1990). Otoliths recovered from the stomach contents or scats of larger fish or mammals have also been used to estimate prey size (Harkonen, 1986).

In this study, otoliths from cod (Gadus morhua), haddock (Melanogrammus aeglefinus), pollock (Pollachius virens), silver hake (Merluccius bilinearis), plaice (Hippoglossoides platessoides), redfish (Sebastes marinus), mackerel (Scomber scombrus) and herring (Clupea harengus) were examined to determine relationships between otolith dimensions and fish length. Comparison of otolith dimensions between sexes for redfish, which are known to have sex-specific growth rates (Sandeman, 1957), was included in the study. Otolith parameters were determined and the relative significance of each parameter for estimating fish length was used to minimize the number of required measurements while still providing an acceptable estimate of fish length.

\section{Materials and Methods}

The otolith is the primary structure used for age determination by the Marine Fish Division of the Department of Fisheries and Oceans, Scotia Fundy Region, and samples are collected from commercial catches and from research survey catches. The number of otoliths collected for individual studies frequently exceeded requirements for age determination and the surplus was used on this study.

In the Marine Fish Division program of otolith collection, extraction of the otoliths required a cut through the cranium to expose them for removal with forceps. Storage media included various chemical solutions as well as dry storage in paper envelopes, depending on the preparation required prior to estimating age. Cod, haddock, pollock and redfish were stored dry in paper envelopes, while silver hake and plaice were stored in glass vials in glycerin solution. Mackerel and herring otoliths were mounted in polystyrene trays (Hunt, 1987). Interpretation of annuli for cod, haddock and pollock was accomplished by examination of cross-sections, 
which required dry storage, while otoliths for other species were examined intact. Relevant sampling data for individual fish were recorded at the time of collection and generally included species, date, location, fork length, sex, maturity stage and weight.

All material used in this study was collected from fish caught in NAFO Divisions 4VWX between 1984 and 1987. No distinction in the specific geographic source of the material was attempted, although some variability in otolith morphology between stocks of the same species is known to occur (Messieh and MacDougall, MS 1984).

Otoliths were examined to ensure they were intact with no missing parts or fractures, and the left and right otolith were considered separately. Specimens with obvious evidence of calcite crystallization (Strong et al., 1986) or other aberrant formations were rejected.

The linear measurements for a generalized Gadidae otolith are shown in Fig. 1. Otolith length was defined as the longest dimension between the anterior and posterior edges of the otolith, and width as the dimension from the dorsal to ventral edge taken at right angles to the length through the focus of the otolith. All measurements were made with the concave (proximal) side of the otolith facing down, to ensure that the anterior and posterior aspect of the otolith were in the same focal plane.

Fork length (to nearest centimeter) was obtained from sampling data. Linear measurements of otolith length and width were obtained using a drawing tube and stereo microscope. A scale was superimposed on the otolith image through the drawing tube and the appropriate measurement read directly from the scale, as described by Hunt (1979).

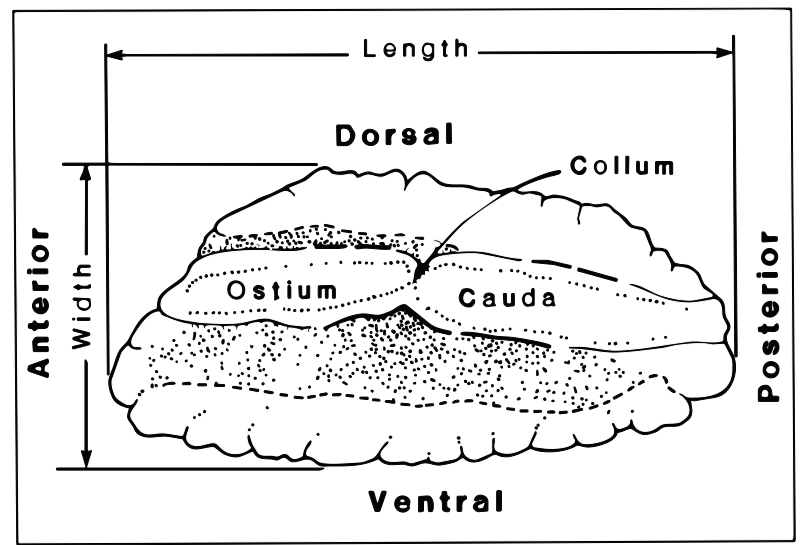

Fig. 1. Definition of linear measurements for a generalized otolith.
For cod, otolith cross-section and longitudinalsection areas were estimated using a digitizing platen. Sections were obtained by embedding otoliths in polyester resin and cutting with a diamond grit blade following the technique described by Strong et al. (MS 1985). Location of the section was based on criteria adopted for age determination which requires a cut through the focus. Locating the focus is important for obtaining cross-sections used for age determination and it is assumed that the focus indicates the focal point for annuli. To assess consistency in the position of the focus, the ratio of length from the anterior edge of the otolith to the focus and total otolith length for cod and haddock was determined.

Up to 10 otolith replicates for each centimeter fish length group over the available length range for each species were measured and the mean for each length group used for subsequent analysis. For both herring and mackerel a random sample rather than a length stratified scheme was used. Individual otoliths which, by visual inspection, were assessed to be outliers were replaced with an additional replicate. Errors in recording fish length at the time of sample collection were assessed to be the source of outliers. Individual otolith weight (in $\mathrm{mg}$ ) was determined using an electronic balance. The wet-stored otoliths were dried with blotting paper prior to weighing.

Otolith volume was estimated by a water displacement method. A known volume of water was placed in a graduated cylinder, groups of up to 10 otoliths within a length group were introduced at a time and the volume of water displaced was determined to the nearest milliliter. Total displacement for all replicates within length groups was determined and the mean individual otolith volume was estimated as the displaced volume divided by number of otoliths in the sample. No correction for atmospheric pressure or air temperature was applied.

Results of an earlier study by the author for mackerel are included in this report. Similar measurement techniques were used but only the relation between fork length and otolith length was examined. Herring otoliths were also examined to determine otolith length.

Inter-relationships between otolith morphological parameters and fish length were determined using a computer analysis package (STATGRAPHICS). For redfish, which have different growth rates between males and females, sex was treated as an additional parameter. Fish length was 
considered the dependent variable in assessing the relationship between otolith dimension and fish size.

\section{Results}

The number of observations on each species and range in fish lengths is given in Table 1. The fish lengths available for each species were those observed in commercial fisheries and research surveys but the extremes of length ranges were undersampled and in some cases fewer than ten replicates were available. The dimensions of the left and right otolith appeared to be similar.

Regression of the difference between left and right otolith on fish length indicated slopes not significantly different from zero with low correlation for length, weight and width. Plaice was the only exception and there appeared to be significant correlation and slope between both the weight and width of the otoliths. Results of regression analysis are given in Table 2 .

Otolith pairs from 167 male and 198 female redfish were examined to obtain mean otolith dimensions for 46 fish length groups. Regression of the difference in otolith length, weight and width parameters of males and females on fish length, given in Table 3, indicated low correlation between sexes with slopes not significantly different from zero. Therefore, subsequent analysis used the mean otolith dimension for males and females combined.

The range in observed values for otolith length, width, weight and volume for each of the species considered is given in Table 4.

Correlation between otolith dimension and fish length was high when a logarithmic transformation was applied to adjust for curvilinearity. A linear regression model was used to determine the relation between the log of fish length and log of otolith dimension. Results of regression analyses are given

TABLE 1. Summary of samples used for otolith morphological measurements.

\begin{tabular}{lrccc}
\hline Species & $\begin{array}{c}\text { Length } \\
\text { range } \\
\text { (cm) }\end{array}$ & $\begin{array}{c}\text { Length } \\
\text { groups }\end{array}$ & $\begin{array}{c}\text { Mean } \\
\text { length } \\
(\mathrm{cm})\end{array}$ & Observations \\
\hline Cod & $9-107$ & 91 & 58 & 397 \\
Haddock & $17-79$ & 62 & 48 & 277 \\
Pollock & $10-100$ & 74 & 56 & 299 \\
Plaice & $10-63$ & 54 & 37 & 253 \\
Silver hake & $9-57$ & 49 & 33 & 224 \\
Redfish (m) & $5-54$ & 46 & 28 & 167 \\
Redfish (f) & $5-54$ & 46 & 28 & 198 \\
Mackerel & $19-42$ & 24 & 30 & 249 \\
Herring & $9-35$ & 26 & 22 & 467 \\
\hline
\end{tabular}

in Table 5. In all cases the regression model appeared to adequately describe the relationship between otolith parameters and fish length with both high correlation and significant estimates for slopes and intercepts. More complex nonlinear models might improve the overall fit but these were not investigated. Plots of the relationship for each of the species examined are given in Fig. 2-8. For mackerel (Fig. 9), no observations at lengths less than $19 \mathrm{~cm}$ were available and extrapolation of the curve for fish lengths less then $19 \mathrm{~cm}$ may not be appropriate. Regression analysis of fish length on otolith for herring is shown in Fig. 10. Considerable variability in the relation between otolith length and fish length was noted for this species. Cleary et al. (MS 1982) and Messieh and MacDougall (MS 1984) document apparent differences in otolith morphology between spawning groups of herring.

All four of the otolith dimensions examined in this study had significant relation to fish length. Individual contribution of parameters was assessed using forward stepwise variable selection in a multiple regression model, with a logarithmic transform for otolith parameters and fish length. Volume, as estimated in this study, was not included since the precision of measurements was much less than that for the other parameters. Results are given in Table 6 and based on comparison of the estimated standard deviation of the predicted fish length (Tables 5 and 6), only slight improvement in the relation with fish length was evident when more than one otolith parameter was included in the model.

Comparison of the shape of curves relating otolith length and weight for cod, haddock and pollock is shown in Fig. 11. Pollock and haddock otoliths had a similar length weight relation while cod otoliths appeared to weigh substantially more at the same otolith length. Differences between species for the relationship of fish length and otolith length and weight are shown in Fig. 12. Of the three, haddock appear to have the largest and heaviest otolith relative to fish length. Regression analysis of the difference between otolith length and weight on fish length resulted in significant slopes and intercepts for all three comparisons (cod/pollock, cod/ haddock, haddock/pollock). The relation between sulcus length (distance from anterior edge to sulcus notch) and fish length for cod and haddock is shown in Fig. 13. The relationship appeared to be consistent over the total otolith length range. The mean ratio of sulcus length to total length was 0.43 for cod and 0.38 for haddock with a small variance for both values.

Cod otolith cross-sections were measured to determine the angle between the dorsal and ventral margins of annuli for fish with eight or more annuli. 
TABLE 2. Results of regression analysis of the difference between left and right otolith dimension on fish length for cod, haddock, pollock, silver hake, plaice and redfish (n.s. = not significant at $95 \%$ level.)

\begin{tabular}{|c|c|c|c|c|}
\hline $\begin{array}{c}\text { Otolith } \\
\text { parameter }\end{array}$ & Intercept & Slope & R-squared & Significance \\
\hline \multicolumn{5}{|c|}{ Cod } \\
\hline Length & $-2.18 \mathrm{E}-4$ & $5.06 \mathrm{E}-5$ & .004 & n.s. \\
\hline Width & $7.19 \mathrm{E}-3$ & $1.32 E-4$ & .068 & n.s. \\
\hline Weight & $-1.26 \mathrm{E}-3$ & $1.88 \mathrm{E}-5$ & .004 & n.s. \\
\hline \multicolumn{5}{|c|}{ Haddock } \\
\hline Length & $4.73 \mathrm{E}-3$ & $-1.37 E-4$ & .009 & n.s. \\
\hline Width & $2.96 \mathrm{E}-3$ & $1.57 \mathrm{E}-5$ & .004 & n.s. \\
\hline Weight & $-6.67 E-6$ & $-9.71 E-6$ & .003 & n.s. \\
\hline \multicolumn{5}{|c|}{ Pollock } \\
\hline Length & $-4.43 E-4$ & $-6.59 E-6$ & .000 & n.s. \\
\hline Width & $6.78 \mathrm{E}-3$ & $-1.68 E-4$ & .049 & n.s. \\
\hline Weight & $3.03 E-3$ & $-1.04 \mathrm{E}-4$ & .214 & n.s. \\
\hline \multicolumn{5}{|c|}{ Silver hake } \\
\hline Length & $3.00 \mathrm{E}-3$ & $-7.56 \mathrm{E}-5$ & .002 & n.s. \\
\hline Width & $-1.61 E-3$ & $7.00 \mathrm{E}-5$ & .019 & n.s. \\
\hline Weight & $2.48 \mathrm{E}-4$ & $5.71 \mathrm{E}-6$ & .001 & n.s. \\
\hline \multicolumn{5}{|c|}{ Plaice } \\
\hline Length & $-2.62 E-3$ & $3.01 \mathrm{E}-5$ & .014 & n.s. \\
\hline Width & $-8.35 E-3$ & $5.87 \mathrm{E}-4$ & .436 & s. \\
\hline Weight & $-6.44 \mathrm{E}-3$ & $3.29 \mathrm{E}-4$ & .785 & s. \\
\hline \multicolumn{5}{|c|}{ Redfish (females) } \\
\hline Length & $8.66 \mathrm{E}-3$ & -3.2979 & .050 & n.s. \\
\hline Width & $6.43 E-3$ & $5.04 \mathrm{E}-4$ & .003 & n.s. \\
\hline Weight & $3.45 \mathrm{E}-4$ & $2.93 E-5$ & .002 & n.s. \\
\hline \multicolumn{5}{|c|}{ Redfish (males) } \\
\hline Length & 0.0177 & $-8.57 E-4$ & .143 & n.s. \\
\hline Width & $-8.45 E-3$ & $5.57 \mathrm{E}-4$ & .175 & n.s. \\
\hline Weight & $-3.77 \mathrm{E}-4$ & 4.13E-5 & .006 & n.s. \\
\hline
\end{tabular}

TABLE 3. Results of regression analysis of difference between male and female otolith dimensions on fish length for redfish (n.s. = not significant at $95 \%$ level.)

\begin{tabular}{lrrcc}
\hline \hline Parameter & Intercept & Slope & Correlation & Significance \\
\hline Length & -0.0174 & $7.00-4$ & .038 & n.s. \\
Width & $4.12 \mathrm{E}-3$ & $-3.99 \mathrm{E}-4$ & .009 & n.s. \\
Weight & 0.0145 & $-6.93 \mathrm{E}-4$ & .072 & n.s. \\
\hline
\end{tabular}

In general, the angle decreased from $160^{\circ}-150^{\circ}$ for the first annulus to $125^{\circ}-130^{\circ}$ at the periphery. A typical cross section is shown in Fig. 14.
Otolith density $(\mathrm{g} / \mathrm{ml})$, defined as weight divided by volume, was determined and results are as follows:

\begin{tabular}{lc}
\hline Species & Density $(\mathrm{g} / \mathrm{ml})$ \\
\hline Haddock & 2.677 \\
Pollock & 2.427 \\
Silver hake & 2.739 \\
Plaice & 2.559 \\
Redfish (male) & 2.423 \\
Redfish (female) & 2.381 \\
\hline
\end{tabular}

Silver hake appeared to have the greatest density, although the calculated value may have been 
HUNT: Morphological Characteristics of Otoliths for Selected Fish

TABLE 4. Range of observed otolith dimensions for cod, haddock, pollock, silver hake, plaice, redfish, mackerel and herring.

\begin{tabular}{lcccc}
\hline \hline Species & $\begin{array}{c}\text { Length } \\
(\mathrm{cm})\end{array}$ & $\begin{array}{c}\text { Width } \\
(\mathrm{cm})\end{array}$ & $\begin{array}{c}\text { Weight } \\
(\mathrm{g})\end{array}$ & $\begin{array}{c}\text { Volume } \\
(\mathrm{ml})\end{array}$ \\
\hline Cod & $0.42-2,26$ & $0.17-1.12$ & $0.01-1.34$ & $0.03-0.50$ \\
Haddock & $0.87-2.48$ & $0.33-1.02$ & $0.05-1.25$ & $0.03-0.40$ \\
Pollock & $0.48-2.31$ & $0.19-0.77$ & $0.01-0.83$ & $0.12-0.30$ \\
Silver hake & $0.48-2.77$ & $0.20-0.67$ & $0.01-0.28$ & $0.01-0.11$ \\
Plaice & $0.25-1.18$ & $0.20-0.81$ & $0.01-0.17$ & $0.01-0.07$ \\
Redfish & $0.23-2.19$ & $0.14-1.29$ & $0.01-0.79$ & $0.01-0.34$ \\
Mackerel & $0.16-0.38$ & - & - & - \\
Herring & $0.19-0.53$ & - & - & - \\
\hline
\end{tabular}

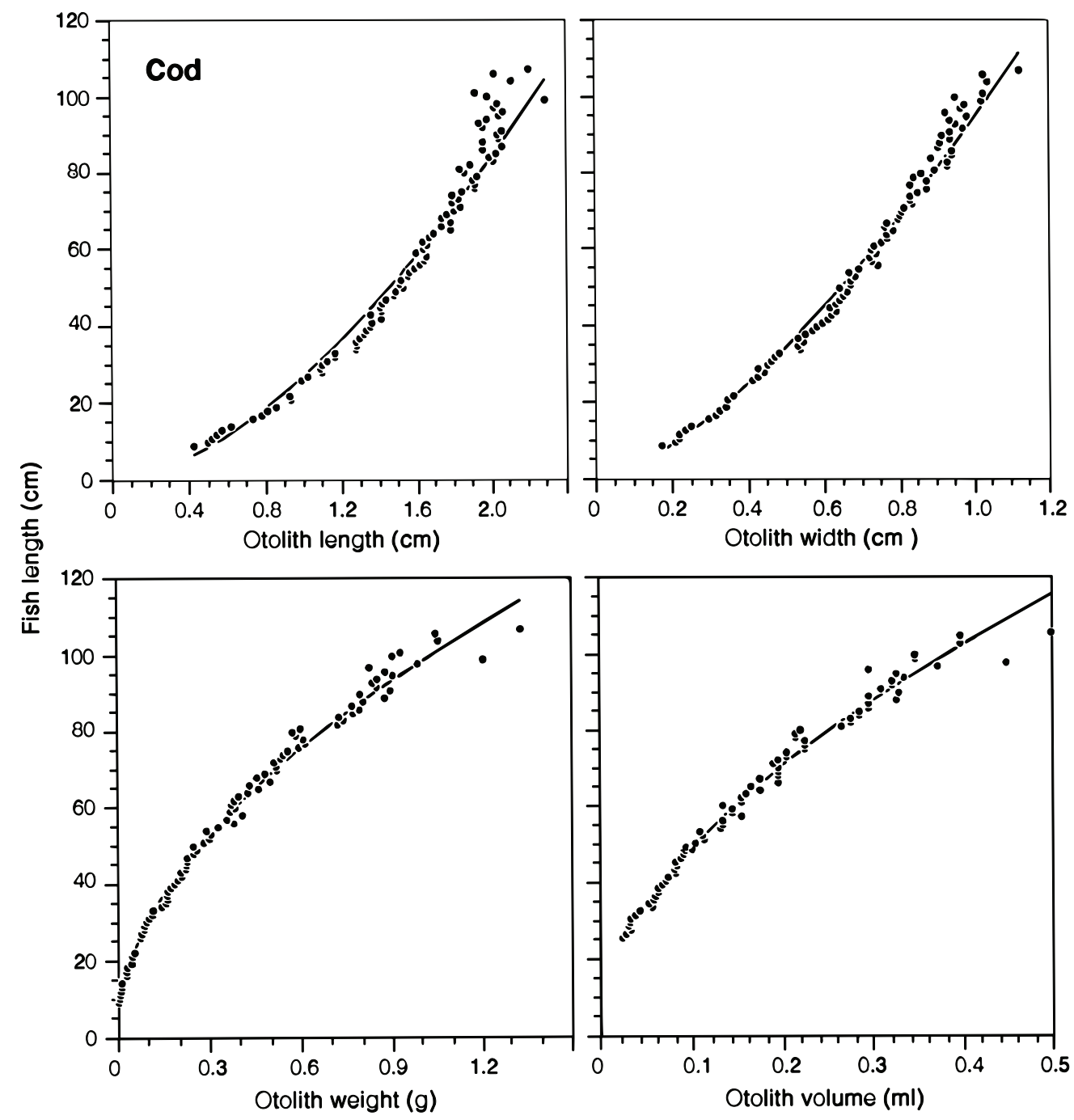

Fig. 2. Results of regression analysis of log fish length on log otolith length, width, weight and volume for cod. 
TABLE 5. Results of regression analysis of log fish length on log otolith dimension for cod, haddock, pollock, silver hake, plaice, redfish, herring and mackerel (Length and width in $\mathrm{cm}$, weight in $\mathrm{g}$, volume in $\mathrm{ml}$ ).

\begin{tabular}{|c|c|c|c|c|}
\hline Parameter & Intercept & Slope & $\mathrm{R}^{2}$ & $\mathrm{SD}^{\mathrm{a}}$ \\
\hline \multicolumn{5}{|c|}{ Cod } \\
\hline Length & 3.31381 & 1.62355 & .988 & 0.0955 \\
\hline Width & 4.55876 & 1.44950 & .995 & 0.0588 \\
\hline Weight & 4.59250 & 0.52204 & .998 & 0.0407 \\
\hline Volume & 5.14638 & 0.55299 & .995 & 0.0381 \\
\hline Cross-section & 5.52661 & 0.76109 & .994 & 0.0661 \\
\hline Long-section & 4.83970 & 0.73491 & .987 & 0.0977 \\
\hline \multicolumn{5}{|c|}{ Haddock } \\
\hline Length & 2.97753 & 1.58465 & .993 & 0.0494 \\
\hline Width & 4.45253 & 1.51933 & .994 & 0.0479 \\
\hline Weight & 4.40255 & 0.54186 & .996 & 0.0409 \\
\hline Volume & 5.0058 & 0.57233 & .997 & 0.0352 \\
\hline \multicolumn{5}{|c|}{ Pollock } \\
\hline Length & 3.25104 & 1.62506 & .990 & 0.0766 \\
\hline Width & 5.12386 & 1.84892 & .983 & 0.1015 \\
\hline Weight & 4.75561 & 0.55143 & .994 & 0.0626 \\
\hline Volume & 5.53144 & 0.67448 & .983 & 0.1003 \\
\hline \multicolumn{5}{|c|}{ Silver hake } \\
\hline Length & 3.01115 & 1.02758 & .994 & 0.0548 \\
\hline Width & 4.55998 & 1.48785 & .976 & 0.1099 \\
\hline Weight & 4.56558 & 0.46300 & .992 & 0.0644 \\
\hline Volume & 4.94456 & 0.44018 & .983 & 0.1054 \\
\hline \multicolumn{5}{|c|}{ Plaice } \\
\hline Length & 4.03390 & 1.24253 & .995 & 0.0514 \\
\hline Width & 4.47723 & 1.32442 & .996 & 0.0452 \\
\hline Weight & 5.11241 & 0.51604 & .996 & 0.0478 \\
\hline Volume & 5.92062 & 0.60349 & .976 & 0.1114 \\
\hline \multicolumn{5}{|c|}{ Redfish } \\
\hline Length & 3.12728 & 1.14365 & .993 & 0.0718 \\
\hline Width & 3.68726 & 1.14770 & .991 & 0.0824 \\
\hline Weight & 4.06779 & 0.41959 & .991 & 0.0805 \\
\hline Volume & 4.65604 & 0.49454 & .994 & 0.0674 \\
\hline \multicolumn{5}{|c|}{ Herring } \\
\hline Length & 5.66790 & 1.20621 & .996 & 0.0365 \\
\hline \multicolumn{5}{|c|}{ Mackerel } \\
\hline Length & 5.24345 & 1.09623 & .989 & 0.0364 \\
\hline
\end{tabular}

${ }^{a} \mathrm{SD}=$ standard deviation of estimated fish length.

inflated by the residuals of storage liquid (glycerin) absorbed or left on the otolith surface when weights were determined. There appeared to be a positive relation between otolith density and fish length within species but regression analysis explained less than $30 \%$ of the variance for all species. This may be

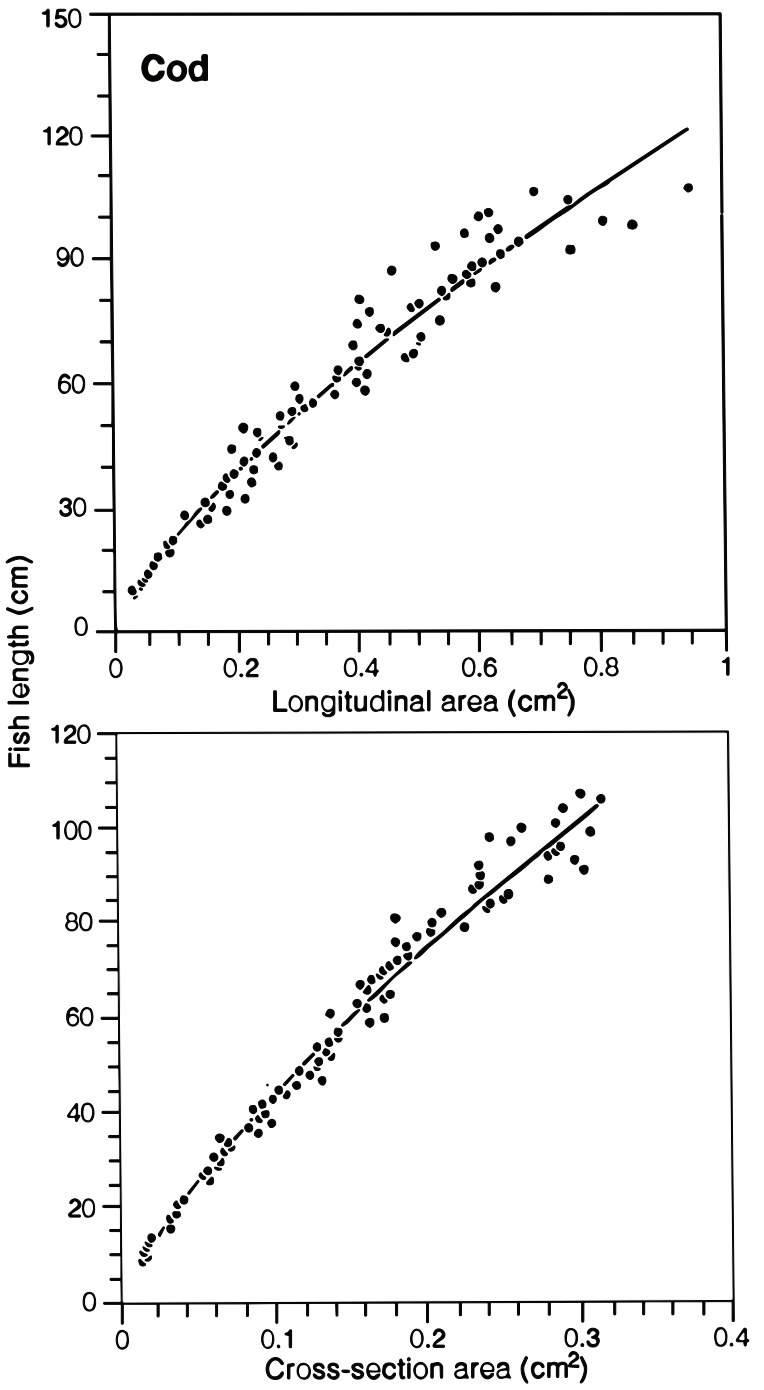

Fig. 3. Results of regression analysis of log fish length on log otolith cross-section and log longitudinal area for cod.

attributable to the use of mean values for weight and volume within length groups which would reduce the influence of individuality for each fish and could mask a more significant relationship.

\section{Discussion}

The relationships of otolith length, weight, width and volume with fish length were species-specific, and even within closely related species considerable differences occurred. Results indicated that otolith linear dimensions were related to fish length by a curvilinear model. For some species (cod, haddock, pollock) increases in linear dimensions (length and width) appeared not to keep pace with increases in fish length and the otolith may reach a 
TABLE 6. Results of stepwise variable selection using multiple regression model for log fish length and log otolith dimension.

\begin{tabular}{|c|c|c|}
\hline $\begin{array}{c}\text { Variable in model } \\
\text { ordered by significance }\end{array}$ & Coefficient & $\mathrm{SD}^{\mathrm{a}}$ \\
\hline \multicolumn{3}{|c|}{ Cod } \\
\hline Length & -0.4038 & \\
\hline Weight & 0.5228 & \\
\hline Width & 0.3539 & \\
\hline Intercept & 4.9002 & 0.0377 \\
\hline \multicolumn{3}{|c|}{ Haddock } \\
\hline Weight & 0.5419 & \\
\hline Intercept & 4.4026 & 0.0409 \\
\hline \multicolumn{3}{|c|}{ Pollock } \\
\hline Weight & 0.5514 & \\
\hline Intercept & 4.7556 & 0.0626 \\
\hline \multicolumn{3}{|c|}{ Silver hake } \\
\hline Length & 0.8606 & \\
\hline Width & 0.2529 & \\
\hline Intercept & 3.2720 & 0.0514 \\
\hline \multicolumn{3}{|c|}{ Redfish } \\
\hline Length & 1.1437 & \\
\hline Intercept & 3.1273 & 0.0718 \\
\hline \multicolumn{3}{|c|}{ Plaice } \\
\hline Length & 0.4756 & \\
\hline Width & 0.8205 & \\
\hline Intercept & 4.3098 & 0.0413 \\
\hline
\end{tabular}

limiting size before maximum fish length was achieved. However, for the other species examined in this study a more linear relation with fish length was evident. Otolith weight and volume appeared to be limited by fish length.

Several authors have noted that otolith growth may reach a linear asymptote while continuing to thicken and increase in weight (Beamish, 1979). This was confirmed in the present study which indicated a change in the morphology of otolith cross sections. Measurements were generally taken as a straight line radius from the nucleus to the zone being examined and the impact of allometric growth was not taken into consideration. This would have resulted in underestimates of fish size.

The constant ratio between otolith sulcus length and fish length confirmed that otolith cross sections provide a reliable surface for interpretation of annuli required for age determination. If the ratio were not constant, sectioning could miss the annuli located near the center since the external reference point (sulcus notch) used to locate the section would not correspond to the internal origin of early annuli.
The lack of significant difference between the left and right otolith for all but plaice is consistent with the observation that the otolith pair are mirror images of each other. For plaice, as well as other flatfish species, it has been noted by the author that differences in the otolith pair are frequently present. In these cases the smaller of the pair is rejected for age determination. The influence of body rotation during the developmental stages may be a factor resulting in the differences in the pair.

A relationship between otolith dimension and fish length has been used in identifying prey size from stomach content samples. Harkonen (1986) discusses some of the problems associated with this technique. Results of this study suggested that otolith length may be the most appropriate for fish at the lower end of the size range but weight has more discrimination at larger lengths. However, given that both otolith weight and linear dimensions were strongly correlated with the fish length, it may be more appropriate to select only one for prediction of fish length. Of the two, otolith weight is the preferred choice because precision of the estimate is higher than that for otolith length; no measuring 


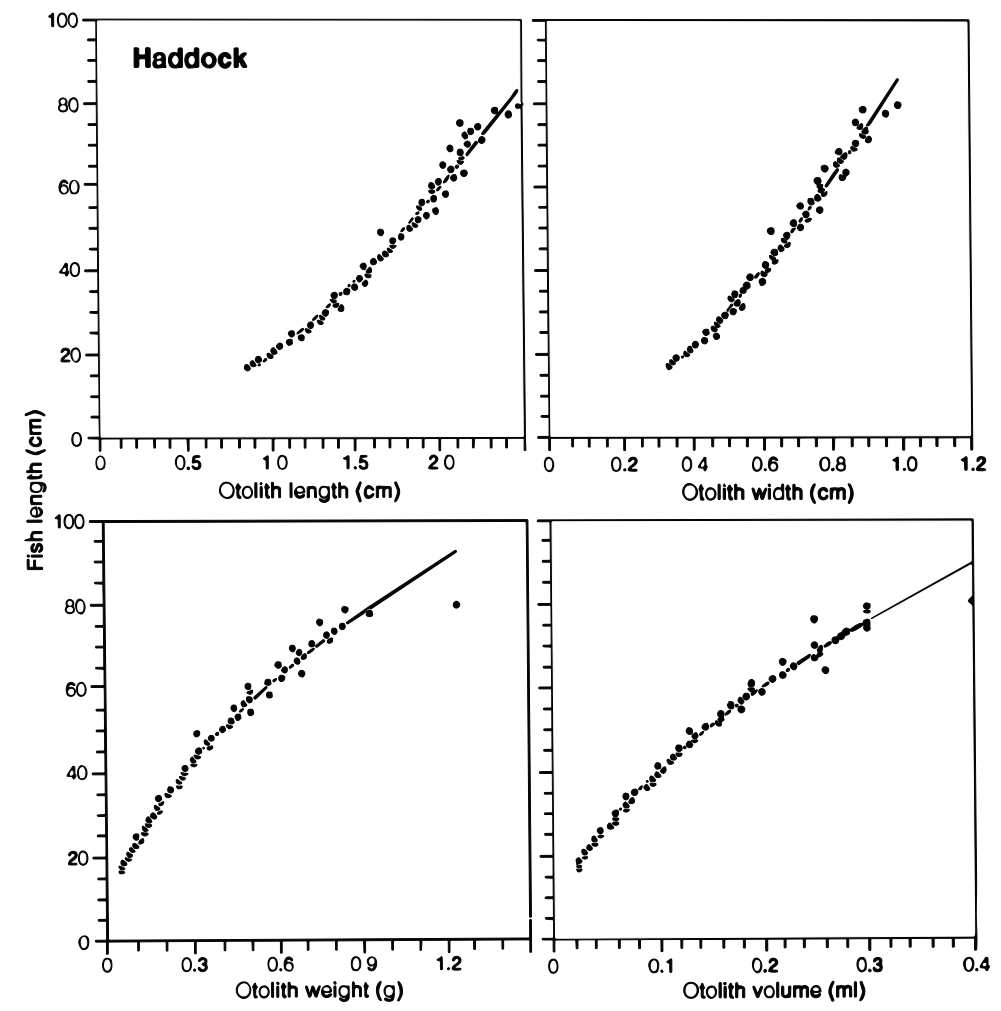

Fig. 4. Results of regression analysis of log fish length on log otolith length, width, weight and volume for haddock.
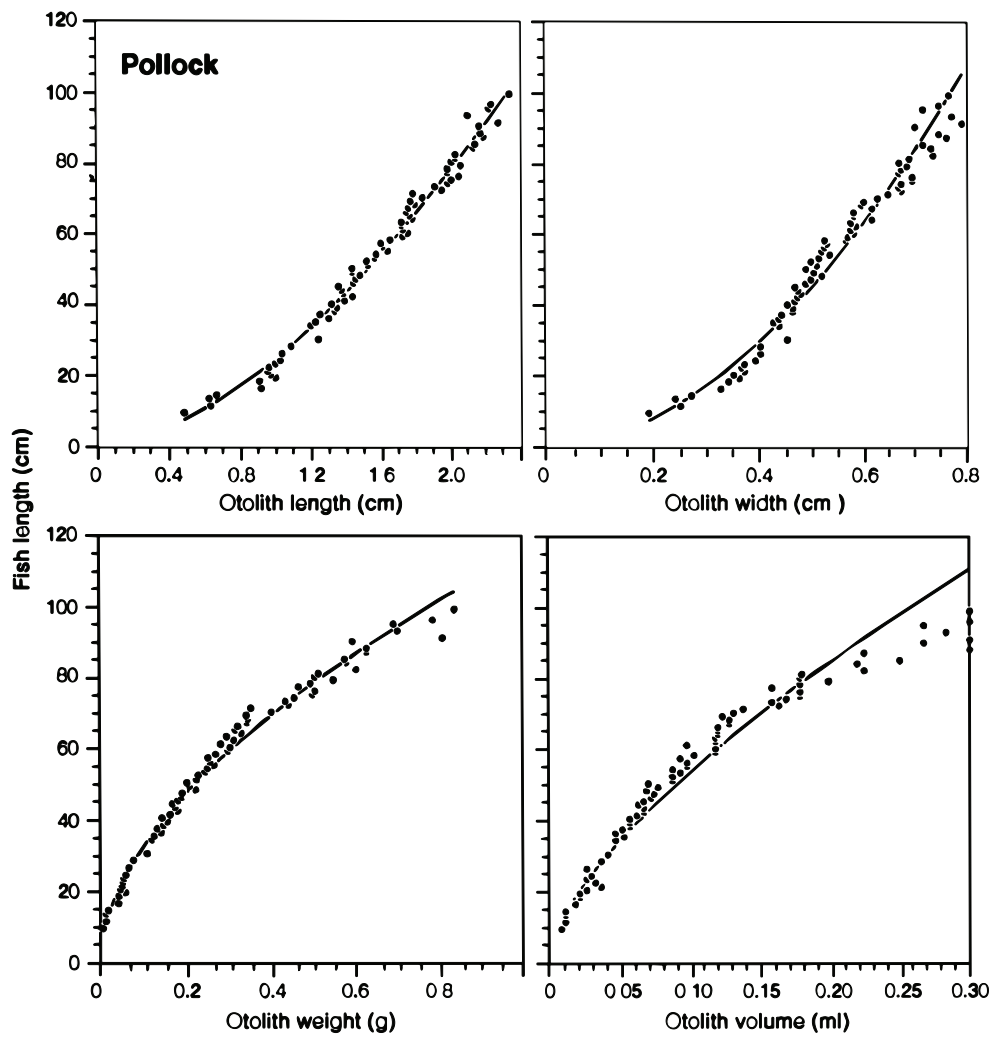

Fig. 5. Results of regression analysis of log fish length on log otolith length, width, weight and volume of pollock. 


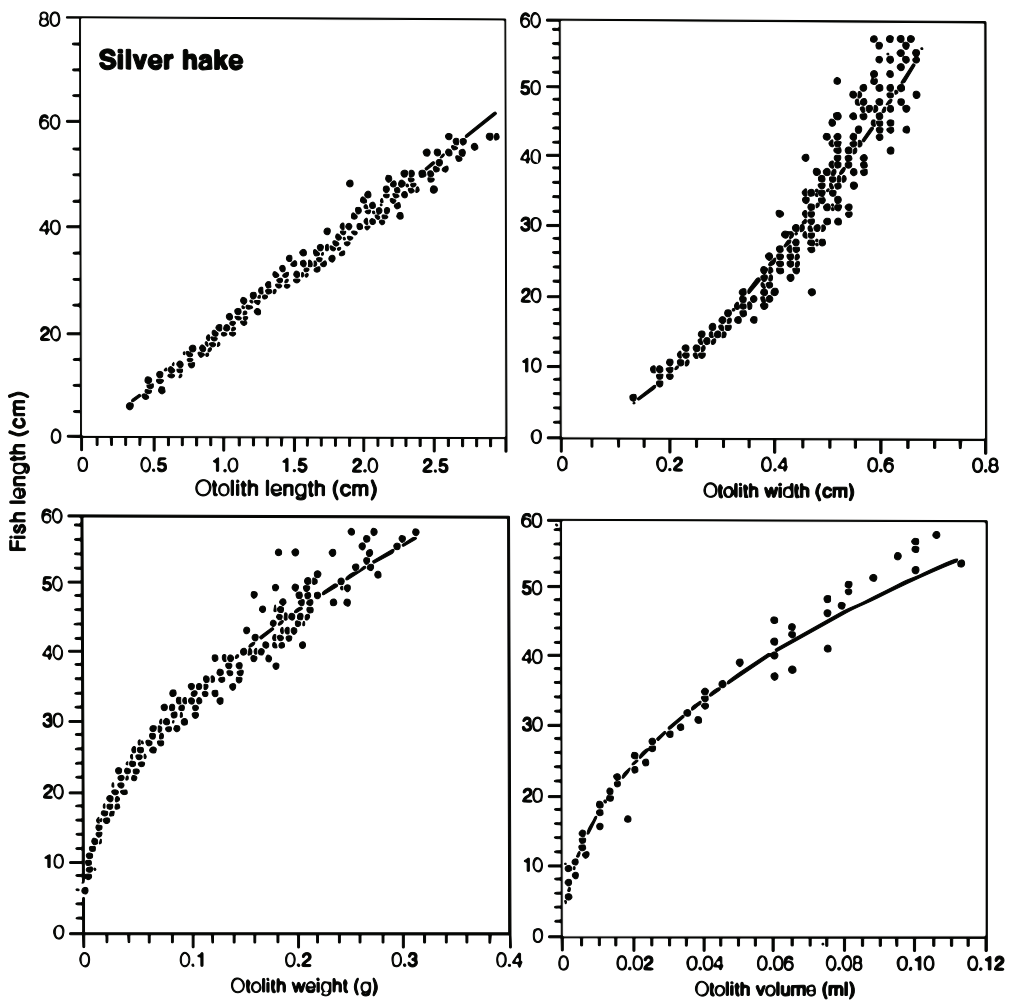

Fig. 6. Results of regression analysis of log fish length on log otolith length, width, weight and volume for silver hake.
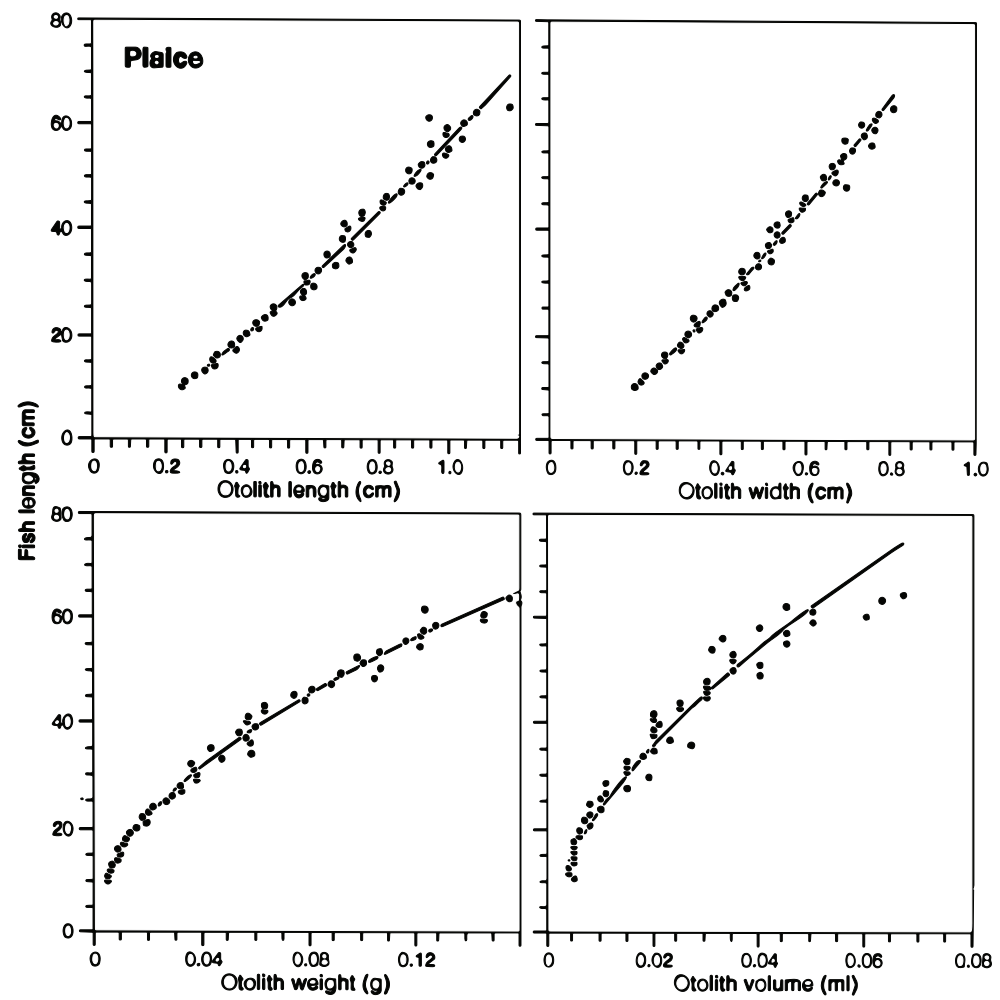

Fig. 7. Results of regression analysis of log fish length on log otolith length, width, weight and volume of plaice. 

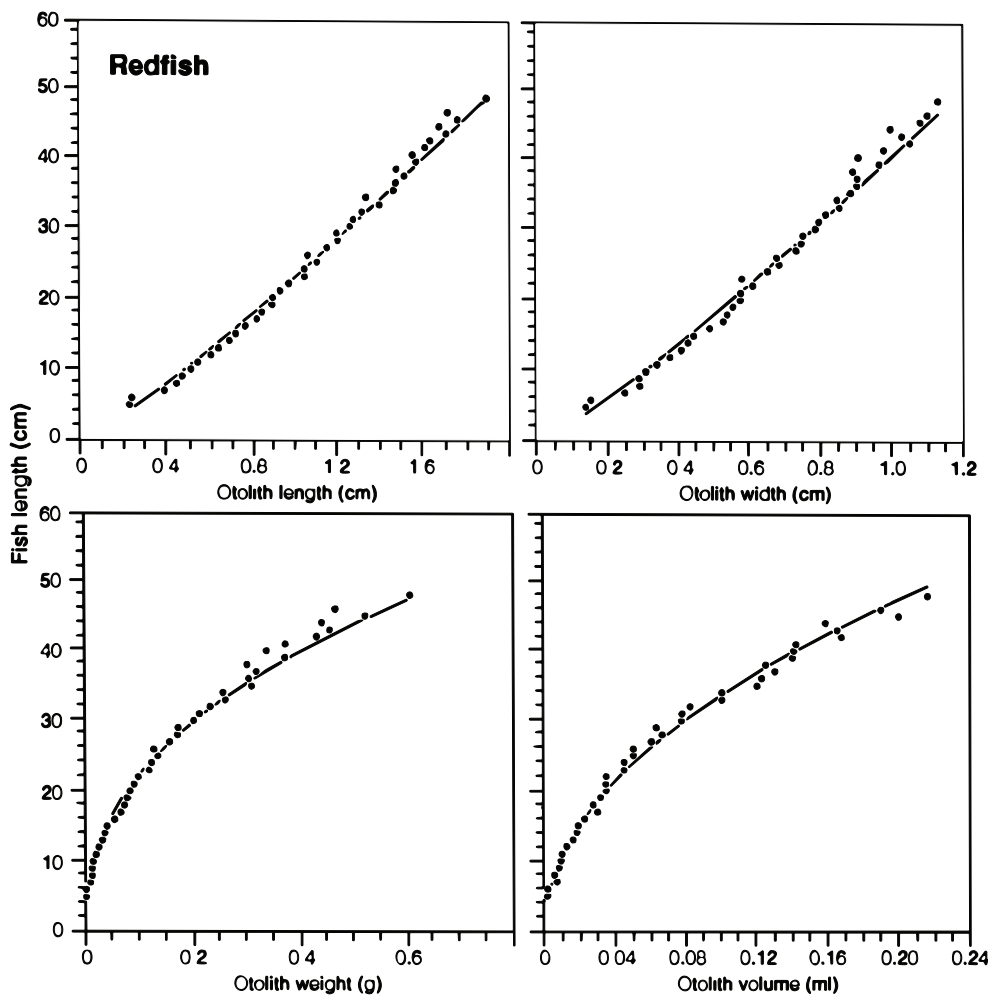

Fig. 8. Results of regression analysis of log fish length on log otolith length, width, weight and volume for redfish.

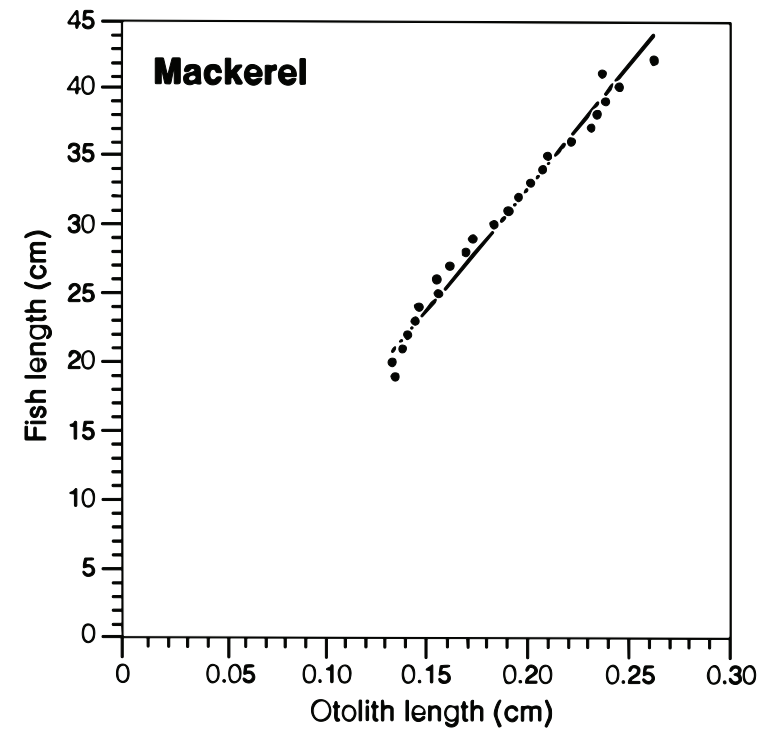

Fig. 9. Results of regression analysis of log fish length on log otolith length for mackerel. 


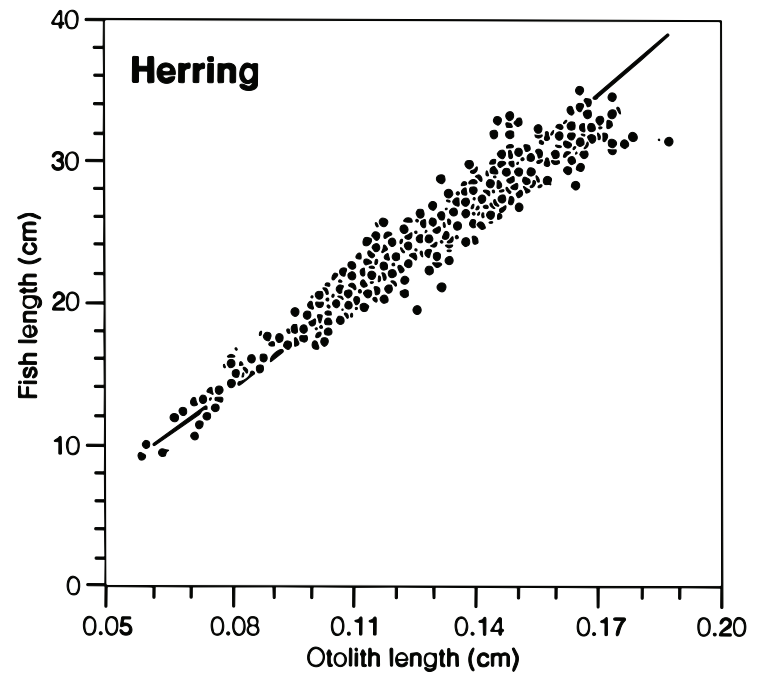

Fig. 10. Results of regression analysis of log fish length on log otolith length for herring.

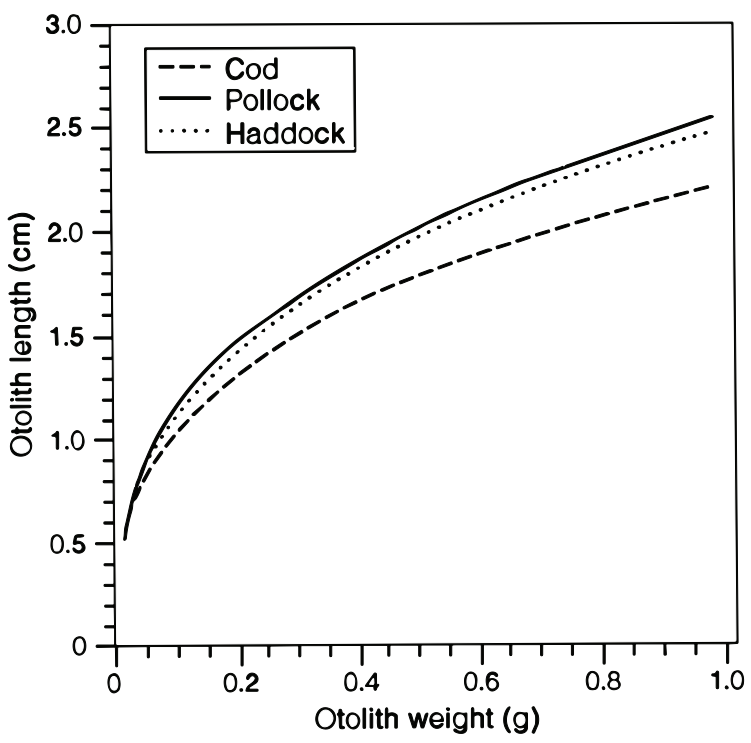

Fig. 11. Comparison of otolith length/weight relationships for cod, haddock and pollock.

devices, other than an electronic balance, are required; and changes in linear growth rate are avoided. Use of a multivariate model is also not justified given the additional work required to measure several parameters with only slight improvement in the precision of estimated fish length.

Erosion of the otolith surface, while passing through the digestive tract of predators, may have a substantial impact on the estimated size of the prey. Otoliths recovered from stomach contents or feces of fish or marine mammals generally

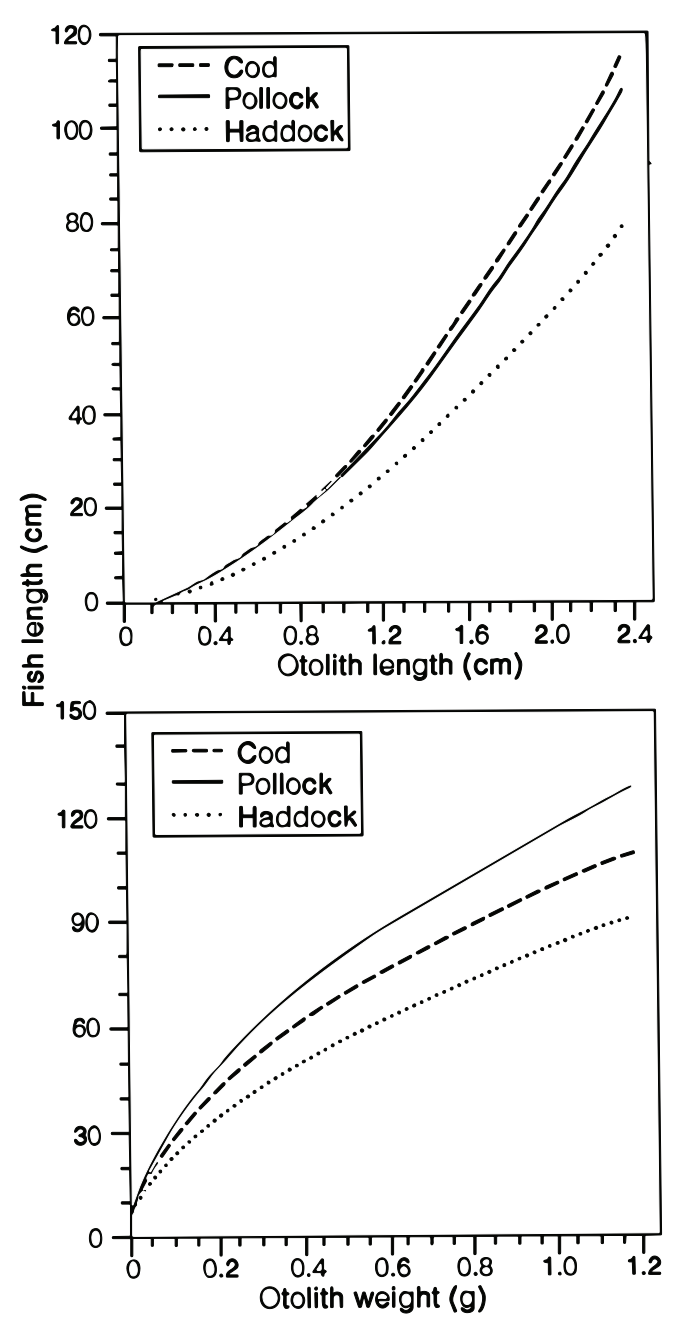

Fig. 12. Comparison of relationships between otolith length and weight with fish length for cod, haddock and pollock.

show considerable erosion (10-50\%) although the general morphological outline may be retained (pers. obs.). Failure to take into account the extent of erosion would lead to underestimates of the size of prey species. For example, the otolith from a $40 \mathrm{~cm}$ cod subjected to a $20 \%$ erosion in length would give a predicted fish length of $27.6 \mathrm{~cm}$ based on the otolith length relationship and $31.8 \mathrm{~cm}$ based on the otolith weight relationship. Estimates of age derived from recovered otoliths may also be biased downward as the edge (and most recent annuli) are eroded from the perimeter of the otolith.

The demonstrated curvilinear relationships between otolith dimension and fish length have implications for back-calculation of length-at-age. Techniques which assume direct proportionality (linear with zero intercept) for a species with a curvilinear 


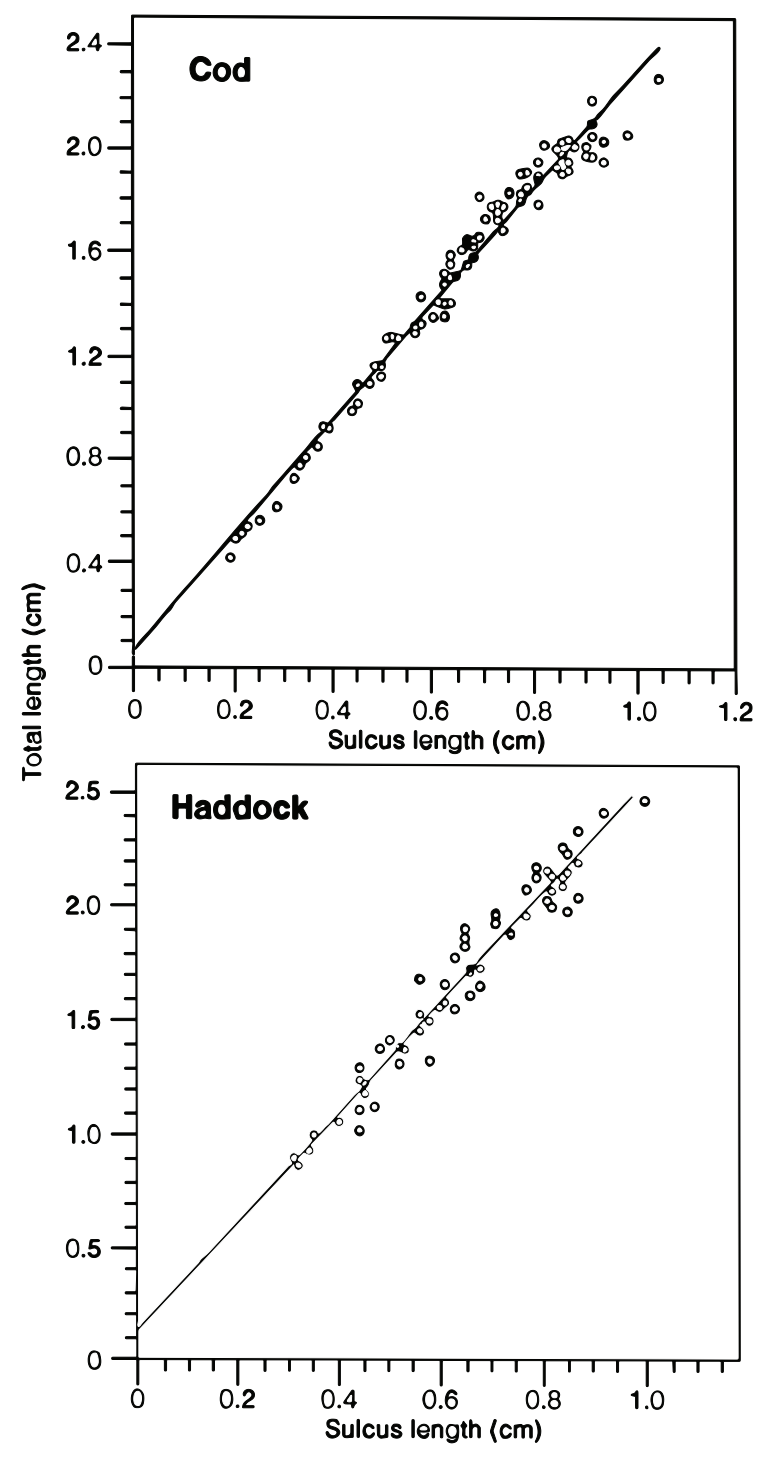

Fig. 13. Results of regression analysis of sulcus length and total otolith length for cod and haddock.

relation will produce biased estimates of back-calculated length-at-age. Bartlett et al. (1984) suggest the use of covariance for determining the most appropriate model to use in back-calculating and assessing the validity of results. Weisberg (1986) also examine models for back-calculation of length and suggest the incorporation of age and year effects. However, individual age and lengths are required for such an analysis and were not available for this study.

The coarse estimate of otolith density and the possible correlation with otolith (and fish) size indicates further analysis should be undertaken. Casselman (1974) reports on a study which demonstrates a positive correlation between otolith spe-

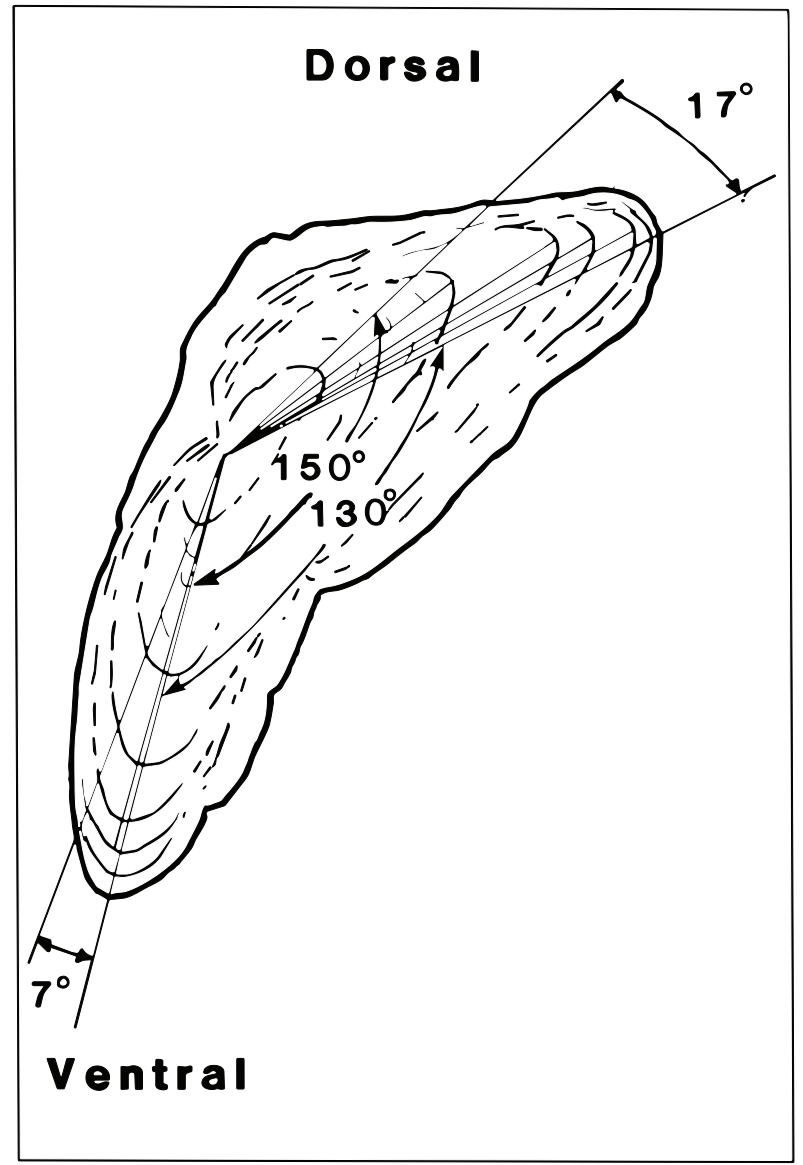

Fig. 14. Changes observed in the angle between the dorsal/ventral extremes of annuli in cod otolith cross sections.

cific gravity and otolith age. The potential application of this relationship for age validation studies will be examined in a future study after age determination of samples is completed.

\section{Acknowledgments}

Two anonymous reviewers provided many helpful comments on both the structure and analysis of an earlier version of the report. Their comments resulted in a much improved manuscript and their assistance is appreciated. The author extends his thanks to the numerous individuals of the Marine Fish Division involved in both the collection and measurement of otoliths.

\section{References}

BARTLETT, J. R., P. F. RANDERSON, R. WILLIAMS, and D. M. ELLIS. 1984. The use of analysis of covariance in back in back-calculation of growth in fish. J. Fish Biol., 24: 201-213.

BEAMISH, R. J. 1979. Differences in the age of Pacific hake (Merluccius productus) using whole otoliths 
and sections of otoliths. J. Fish Res. Board Can , 36

36 $141-151$

BOEHLERT, B. W. 1985. Using objective criteria and multiple regression models for age determination in fish. Fish. Bull. U. S., 83: (2) 103-119.

CASSELMAN, J. M. 1974. In, Ageing of Fish, Edited by T. B. Bagenal, Unwin Bro. Ltd., p. 14-27. ISBN 09502121 13.

CHILTON, D. E., and R. J. BEAMISH. 1982. Age determination methods for fishes studied by the Groundfish Program at the Pacific Biological Station. Can. Spec. Pub. Fish. Aquatic Sci., 60: 102 p.

CLEARY, L., J. HUNT, J. MOORES, and D. TREMBLAY. MS 1982. Herring ageing workshop, St. John's, Newfoundland, March 1982. CAFSAC Res. Doc., No. 41.

HARKONEN, T. 1986. Guide to the otoliths of the bony fishes of the Northeast Atlantic. Danbiu Aps. Biological Consultants. Henningsens Alle 58. DK-2900, Hellerup, Denmark. ISBN 87-982290-2-8.

HUNT, J. J. 1979. Back-calculation of length at age from otoliths for silver hake of the Scotian Shelf. ICNAF
Sel. Papers, 5: 11-17.

1987. Herring sampling program in the ScotiaFundy Region, 1975-85. Can. MS Rep. Fish. Aquat. Sci., 1923: iii + $21 \mathrm{p}$.

MESSIEH, S. N., and C. MACDOUGALL. MS 1984. Spawning groups of Atlantic herring in the southern Gulf of St. Lawrence. CAFSAC Res. Doc. No. 74, 28 p.

PAWSON, M. G. 1990. Using otolith weight to age fish. J. Fish. Biol., 36: 521-531.

SANDEMAN, E. J. 1957. A contribution to the problem of age determination and growth rate in Sebastes. ICNAF Spec. Pub., 3: 276-284.

STRONG, M. B., J. HUNT, and R. ROBICHEAU. MS 1985. A new method of preparing Gadoid otoliths. CAFSAC Res. Doc., 70, 13 p.

STRONG, M. B., J. NEILSON, and J. HUNT. 1986. Aberrant crystallization of pollock otoliths. Can. J. Fish. Aquat. Sci., 43: 1457-1463.

WEISBERG, S. 1986. A linear-model approach to backcalculation of fish length. J. Amer. Stat. Assoc., 81: 922-929. 